\title{
Mössbauer, XRD, and SEM Study of FeAl-Based Powder Alloys with Nanoinclusions
}

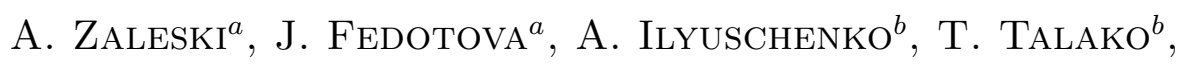
A. Belyaev ${ }^{b}$, A. Letsko ${ }^{b}$ AND J. StAnEK ${ }^{c}$

${ }^{a}$ NC PHEP BSU, M. Bogdanovich 153, 220040 Minsk, Belarus

${ }^{b}$ Institute of Powder Metallurgy, Platonova 41, 220071 Minsk, Belarus

${ }^{c}$ Institute of Physics, Jagiellonian University

Reymonta 4, 30-059 Cracow, Poland

Peculiarities of phase composition and morphology in nanostructured $\left(\mathrm{Fe}_{70} \mathrm{Al}_{30}\right)_{1-x}\left(\mathrm{Al}_{2} \mathrm{O}_{3}\right)_{x}(x=64-80$ wt.\%) powder alloys prepared by self-propagated high temperature synthesis have been studied by ${ }^{57} \mathrm{Fe}$ transmission Mössbauer spectroscopy, scanning electron microscopy, and X-ray diffraction. It has been established that phase composition of alloys has not been affected by $\mathrm{Al}_{2} \mathrm{O}_{3}$ contribution. Contrary, atomic arrangement in $\mathrm{B} 2 \mathrm{FeAl}$ phase depends on the volume fraction of $\mathrm{Al}_{2} \mathrm{O}_{3}$ resulting in the migration of $\mathrm{Al}$ atoms from $\mathrm{B} 2 \mathrm{FeAl}$ lattice.

PACS numbers: 61.66.Dk, 81.20.Ev, 82.80.Ej

\section{Introduction}

Iron aluminides are considered as potential candidates for high temperature structural applications due to their excellent resistance to oxidation and corrosion as well as good mechanical properties at high temperatures and low cost of raw materials. Oxide dispersion strengthening, which involves milling of $\mathrm{FeAl}$ powders with the addition of oxide $\left(\mathrm{Al}_{2} \mathrm{O}_{3}, \mathrm{Y}_{2} \mathrm{O}_{3}\right.$, etc.), is an effective method to improve the high temperature creep resistance and hardness. Self-propagated high temperature synthesis (SHS) is one of the most prospective methods of powder metallurgy. It is a rapid process that usually leads to the formation of non-equilibrium and nonstoichiometric phases accommodating essential concentration of defects effectively influencing the properties of alloys [1-3]. 


\section{Experimental}

$\left(\mathrm{Fe}_{70} \mathrm{Al}_{30}\right)_{1-x}\left(\mathrm{Al}_{2} \mathrm{O}_{3}\right)_{x}(x=64-80$ wt.\%) samples have been prepared using SHS method from $\mathrm{Fe}, \mathrm{Al}$, and $\mathrm{Al}_{2} \mathrm{O}_{3}$ powders that have been subjected to the preliminary mechanical activation in the attritor. Samples have been studied by transmission Mössbauer spectroscopy (TMS), X-ray diffraction (XRD), and scanning electron microscopy (SEM) with attached energy dispersive spectroscopy (EDS) system.

\section{Results}

Phase composition and contribution detected by TMS (see Fig. 1) are in good agreement with that observed by XRD (to be published elsewhere).

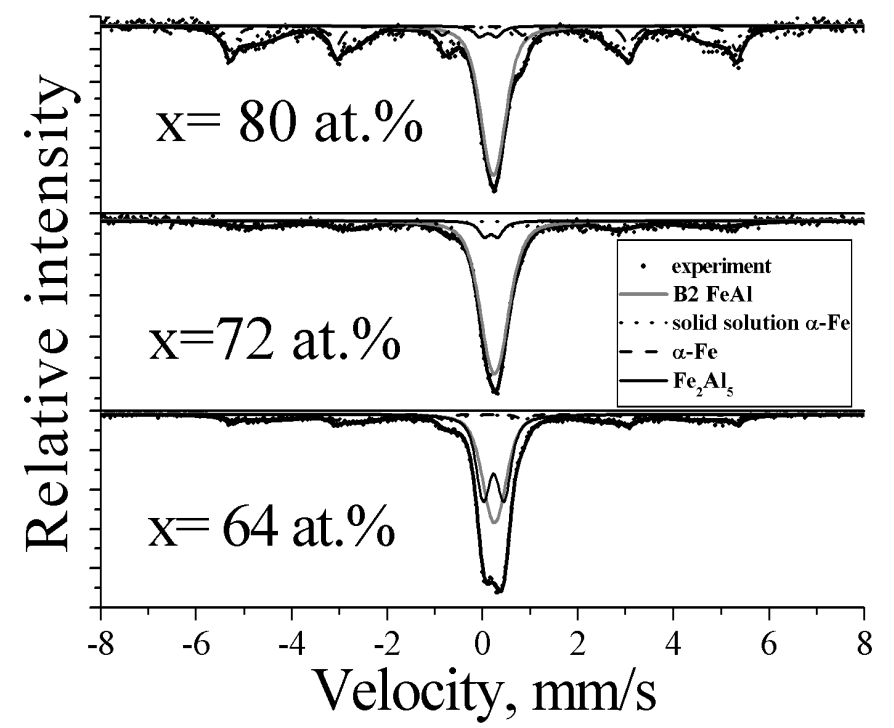

Fig. 1. Mössbauer spectra of the samples $\left(\mathrm{Fe}_{70} \mathrm{Al}_{30}\right)_{1-x}\left(\mathrm{Al}_{2} \mathrm{O}_{3}\right)_{x}$ with $x=64-80$ wt.\%.

TMS investigations confirmed the presence of $\mathrm{B} 2 \mathrm{FeAl}$ and $\mathrm{Fe}_{2} \mathrm{Al}_{5}$ phases as well as some amount of unreacted $\alpha$-Fe in all studied samples. Moreover TMS allowed us to detect the formation of magnetic phase with hyperfine field $H_{\text {eff }}$ close to solid solution $\alpha-\mathrm{Fe}(\mathrm{Al})$ phase which was not observed by XRD. Analysis of hyperfine interaction parameters demonstrated the tendency to decrease the isomer shift $(I S)$ characterizing $\mathrm{B} 2 \mathrm{FeAl}$ phase with growth of $\mathrm{Al}_{2} \mathrm{O}_{3}$ fraction (see Fig. 2).

The observed decrease in $I S$ and consequently the increase in electronic density within Fe nuclei may be the result of decreased Fe $4 s$-electrons screening due to $\mathrm{Al} s p$-electrons charge transfer from the $3 d$-electron Fe atomic shell. It indicates the depletion of $\mathrm{Al}$ in $\mathrm{B} 2 \mathrm{FeAl}$ with the increase in $\mathrm{Al}_{2} \mathrm{O}_{3}$ content before synthesis according to the model suggested in our earlier paper [4]. 


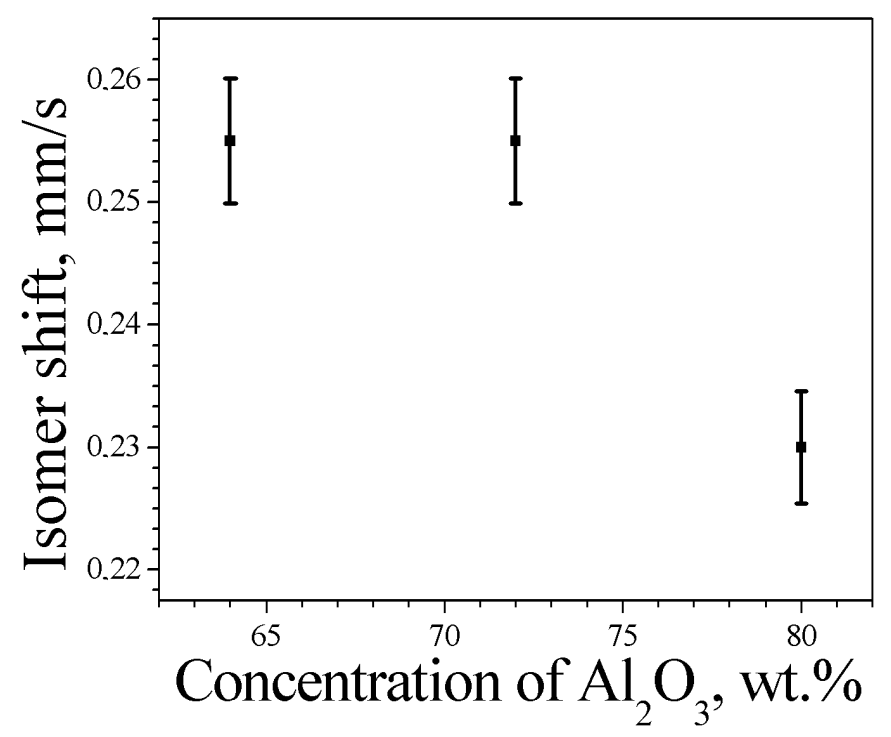

Fig. 2. Dependence of $I S$ characterizing B2 FeAl phase on $\mathrm{Al}_{2} \mathrm{O}_{3}$ concentration.

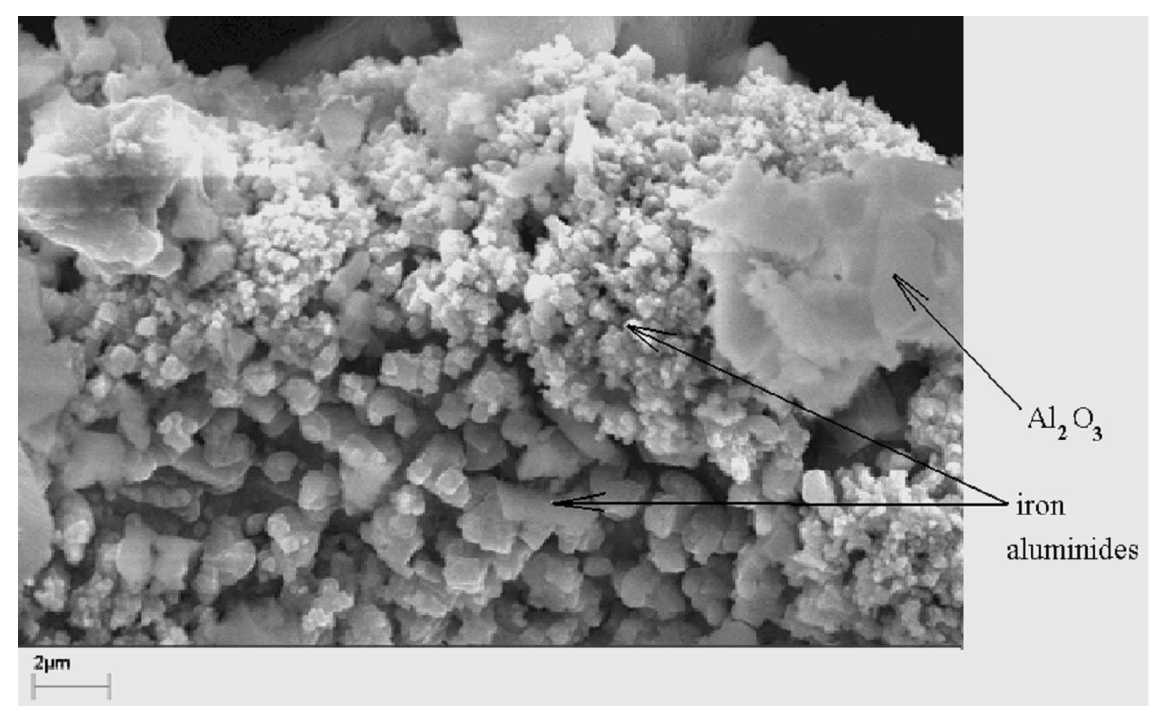

Fig. 3. Results of SEM.

SEM results revealed that a typical grain size of iron-containing phases varies from 50 to $200 \mathrm{~nm}$ (see Fig. 3). The formation of metal oxides $\left(\mathrm{Fe}_{1-x} \mathrm{Al}_{x} \mathrm{O}_{4}\right)$ and diffusion of $\mathrm{Fe}$ atoms in $\mathrm{Al}_{2} \mathrm{O}_{3}$ lattice has not been observed neither by EDS analysis nor by TMS or XRD (as it has been observed for $\mathrm{Fe}-\mathrm{Al}_{2} \mathrm{O}_{3}$ system in [5]). 


\section{Conclusions}

1. It was established that at all studied contributions of $\mathrm{Al}_{2} \mathrm{O}_{3}$ phase composition is mainly represented by $\mathrm{B} 2 \mathrm{FeAl}, \mathrm{Fe}_{2} \mathrm{Al}_{5}, \mathrm{Al}_{2} \mathrm{O}_{3}$, solid solution $\alpha-\mathrm{Fe}(\mathrm{Al})$, unreacted $\alpha-\mathrm{Fe}$, and $\mathrm{Al}$.

2. An addition of $\mathrm{Al}_{2} \mathrm{O}_{3}$ before synthesis causes the migration of $\mathrm{Al}$ atoms from B2 FeAl lattice.

\section{References}

[1] N.S. Stoloff, Mater. Sci. Eng. A 258, 1 (1998).

[2] M. Kogachi, T. Haraguchi, S.M. Kim, Intermetallics 6, 499 (1998).

[3] S. Gialanella, R.S. Brusa, W. Deng, F. Marino, T. Spataru, G. Principi, J. Alloys Comp. 317-318, 485 (2001).

[4] J. Fedotova, A. Ilyuschenko, A. Zaleski, T. Talako, A. Belyaev, A. Letsko, J. Stanek, in: Industrial Appplications of the Mössbauer Effect, Eds. M. Gracia, J.F. Marco, F. Plazaola, AIP Conf. Proc., Vol. 765, American Institute of Physics, New York 2005, p. T7.

[5] P. Matteazi, G. Le Caer, J. Am. Ceram. Soc. 75, 2749 (1992). 